\title{
Edward Ruscha: uma prática fotográfica em transformação
}

\author{
Luciano Bernardino da Costa ${ }^{1}$ \\ Luis Pedro de Almeida Soquetti ${ }^{2}$ \\ DOI 10.20396/eha.vil4.3447
}

Os Estados Unidos do pós-Guerra viveram um período de consolidação de sua influência cultural, política e econômica. Ao oferecer condições financeiras à reconstrução da Europa, o Plano Marshall favoreceu também a ampliação da base produtiva norte-americana associada a um intenso processo de urbanização e construção de um padrão de vida pautado pelo consumo de bens materiais e culturais como signos prosperidade e afirmação de modernidade. A formação de uma robusta classe média tornou-se, então, expressão e síntese deste crescimento econômico sem precedentes, revigorando o mito do progresso alardeado por uma indústria cultural que passou a disseminar globalmente o modelo americano através de mercadorias, novas tecnologias e entretenimentos, que tem em grande parte a Califórnia como centro produtor.

Ruscha é um dos muitos americanos que buscaram se inserir e participar dessa expansão. Filho de um auditor de Oklahoma, realizava em sua juventude viagens de férias com os pais, usufruindo do acesso crescente ao automóvel e de uma infraestrutura rodoviária que se torna abundante a partir dos anos 50. Optando por realizar sua formação em artes gráficas viaja periodicamente de seu estado, Oklahoma, para Los Angeles. Lá encontra uma efervescente metrópole que se expande nas zonas centrais e, principalmente, para os subúrbios onde os núcleos habitacionais vão formar o novo modelo de moradia cercado de todo o aparato tecnológico e simbólico disponível. A capa da Los Angeles Magazine de $1961^{3}$ apresenta uma ilustração dessa paisagem urbana espraiada entremeada por vias expressas carregadas de automóveis sob um pôr do sol cinematográfico entre as montanhas e o deserto da Califórnia. Essa espacialidade e sua dimensão simbólica foram explo-

\footnotetext{
* IAU USP. Este artigo é parte da pesquisa "Fotolivros e espacialidades urbanas em Edward Ruscha", desenvolvida com o apoio Programa Unificado de Bolsas (PUB-USP), durante os anos de 2018-19.

1 Luciano Bernardino da Costa é professor-doutor do Instituto de Arquitetura e Urbanismo da USP São Carlos. Atua como didata na área de Representação e Linguagem. Desenvolve pesquisas junto ao NEC-IAU (Núcleo de Pesquisas de Espacialidades Contemporâneas), tratando de questões relativas à fotografia urbana contemporânea, produção artística e fotográfica dos anos 60 e 70, produção fotográfica brasileira que reporta a questão urbana, e representação, percepção e leitura da paisagem. Seu email é lbcosta45@gmail.com.

2 Graduando em Arquitetura e Urbanismo, bolsista da pesquisa "Fotolivros e espacialidades urbanas em Edward Ruscha" entre os anos de 2018-19. Desenvolveu pesquisas junto ao NEC-IAU (Núcleo de Pesquisas de Espacialidades Contemporâneas) e N.ELAC-IAU ( Núcleo de Pesquisa em Estudos de Linguagem em Arquitetura e Cidade). Seu email é Ipsoquetti@gmail.com.

3 Figura 01.
} 
radas insistentemente pelas mídias construindo uma imagem da cidade como centro da indústria cultural americana.

Dentre os artefatos tecnológicos de consumo particularmente a fotografia, no pós-Segunda Guerra Mundial, gerou um comércio muito lucrativo com a venda de câmeras e filmes para o cidadão médio, multiplicando a quantidade de fotógrafos amadores auxiliados pela facilidade do snap$s h t^{4}$, transformando qualquer viagem de férias ou feriados em potenciais registros. Exemplo disso é o anúncio da Kodak de $1960^{5}$ em que uma família está preparando as bagagens para viajar quando o filho corre segurando uma Kodak instantânea, dizendo: "Ei! Nós quase esquecemos a coisa mais importante!".

Simultaneamente Ruscha desenvolvia seus livros fotográficos, pinturas e serigrafias dialogando com o contexto de produção das cidades estadunidenses, particularmente protagonizado por Los Angeles. Nestes trabalhos explora as estruturas essenciais e ordinárias dessa paisagem urbana emergente como postos de gasolina, estacionamentos, condomínios de apartamento, letreiros comerciais, vias expressas, galpões industriais, lotes à venda e corredores comerciais ${ }^{6}$. A partir de Standard Station, um dos postos de gasolina presente no fotolivro Twentysix Cas Stations ${ }^{7}$ (1962) ele desenvolve pinturas variando a situação do posto padrão ${ }^{8}$, onde aproxima a forma destes postos de combustível com peças publicitárias do período, realizando uma operação de apropriação que desvirtua o significado original ao embaralhar elementos visuais de origens e propósitos distintos.

\section{A banalização da imagem fotográfica e a cultura visual do período}

Em 1963 Ruscha publica o primeiro livro fotográfico, Twentysix Cas Stations, seu conteúdo cumpre literalmente o título sequenciando de forma lacônica vinte e seis postos de gasolina ao longo da Route 66 no trajeto entre sua faculdade em Los Angeles e a casa de seus pais em Oklahoma City. A única informação no livro são os postos, seus nomes e localizações. Não existe uma figura humana nas imagens ou uma preocupação de enquadrar ou representar a paisagem e o ambiente

\footnotetext{
4 Snapshot ou fotografia instantânea é a imagem capturada de forma espontânea e rápida, sem muitas preocupações compositivas e com a automatização de funções como ISO, abertura, exposição e foco. Normalmente associado a fotografia amadora o snapshot foi difundido pela Eastman Kodak para incentivar o registro das fotografias familiares.

5 Figura 02.

6 Na Figura 03 ele estende seu livro Every Building on the Sunset Strip (1967), desenvolvido na forma de uma grande tira fotográfica para cobrir a extensão de toda uma Comercial Strip de Los Angeles.

7 Figura 04

8 Figura 05.
} 


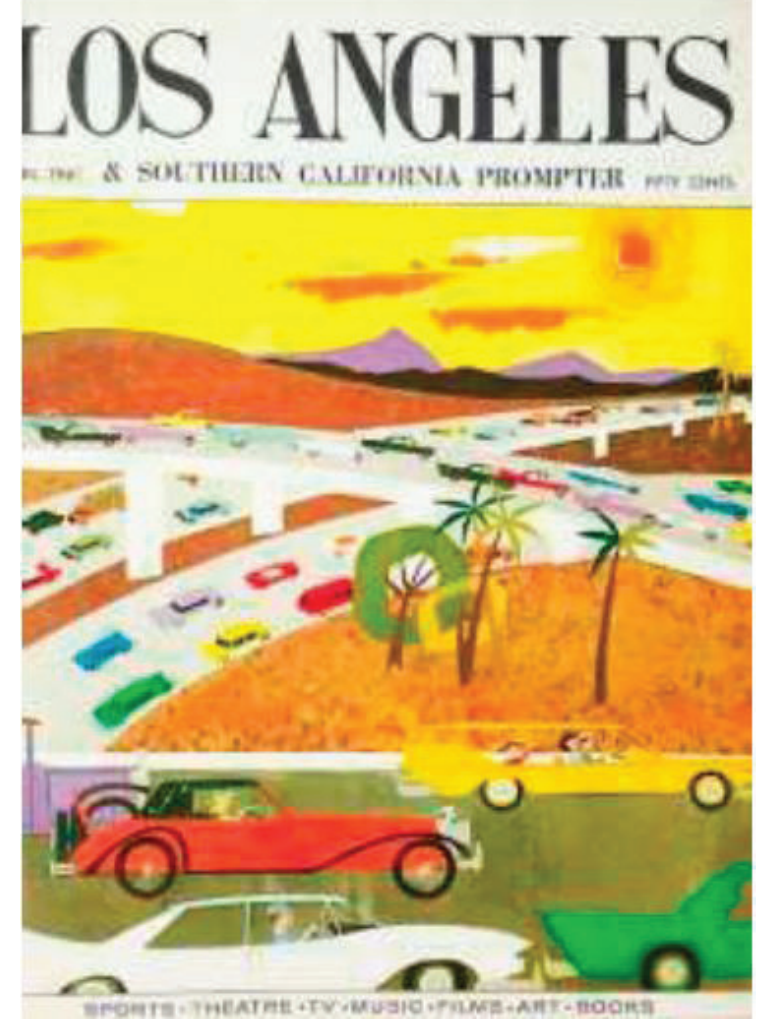

[Figura 01] Capa de Los Angeles Magazine 1961.

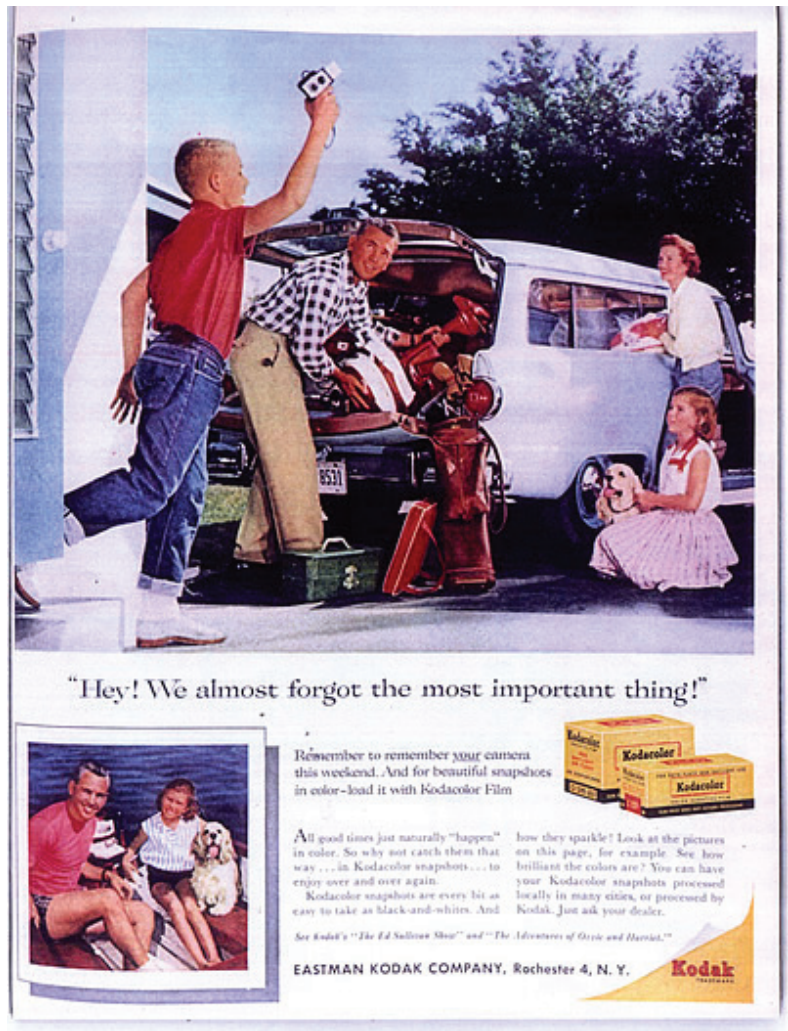

[Figura 02] Publicidade do Snapshot Kodak de 1960.

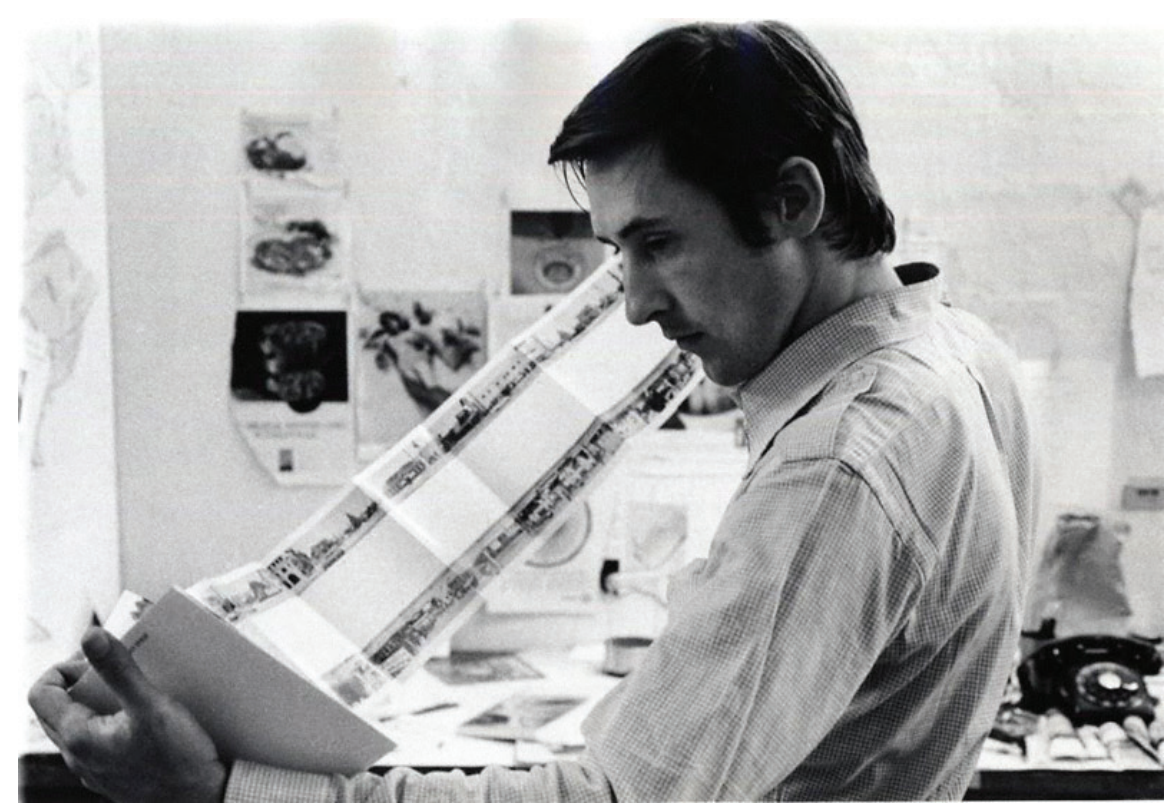

[Figura 03]

Ruscha segurando seu livro Every Building on the Sunset Strip (1967). 
do entorno, com a exceção de algumas fotos onde a estrada ocupa mais espaço no campo do que a própria estação.

Desde a forma como o tema do livro é desenvolvido até quando é distribuído, sequenciam-se vários aspectos com um certo grau de absurdo para um observador desavisado, ou mesmo para um fotógrafo envolvido com as práticas de seu meio: 1) a ideia de fazer um livro com apenas fotos de postos de gasolina onde os únicos elementos textuais são o título, o nome do autor e a legenda de cada estação com seu nome e localização; 2) o despojamento estético das imagens de muitas convenções técnicas da fotografia; 3) a reprodução econômica e sua distribuição a um preço baixo, na maioria das vezes sem nenhuma identificação de originalidade ou número de série; 4) a inexistência de uma narrativa clara que justifique o sequenciamento dos postos de gasolina a não ser a semelhança formal entre os postos; 5) o percurso caótico formado pelas estações sequenciadas, os quais não correspondem a um caminho lógico entre dois pontos mas cheio de voltas desnecessárias, o que abre a dúvida sobre a sua fidelidade como possível mapeamento ou cartografia. $^{9}$

Tais características colocam questões sobre a oposição entre as estratégias adotadas por Ruscha e a cultura visual do período, tanto aquela disseminada pela mídia quanto a pactuada pela produção artística presente no circuito das galerias. Na forma de uma interlocução ambígua, tais estratégias parecem constantemente situarem-se entre obra de arte e periodismo, entre banalidade do registro fotográfico e conceito visual apurado, compondo uma obra desafiadora que dialoga com campos artísticos distintos. A compreensão proposta neste texto passa justamente por discutir algumas das transformações que afetaram a produção artística dos anos 60, em particular aquelas que se apropriam da cultura visual e arquitetônica dirigida às massas associada à desconstrução da “linguagem" fotográfica moderna.

Fotografia documental ou fotografia ficcional

É evidente que as fotografias de Twentysix Gas Stations, assim como de outros trabalhos de Ruscha, não são destinadas a uma apreciação individual mediante qualidades específicas ao meio fotográfico. Mesmo negando a estética e a concepção da foto artística para se aproximar de uma imagem documental, o livro de Ruscha também não pode se enquadrar na categoria de documento

9 Figura 06. 

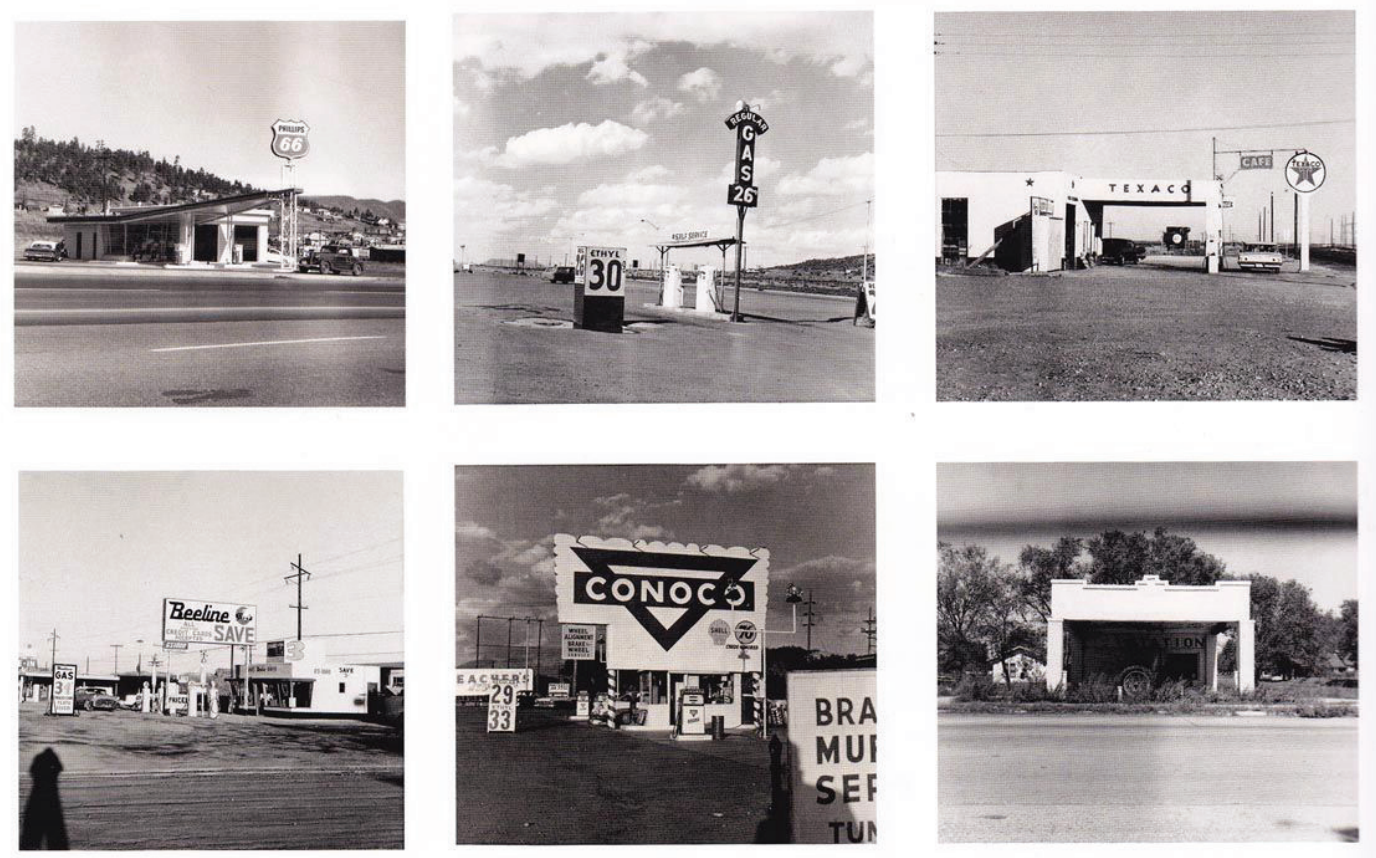

[Figura 04] Ed Ruscha. Twentysix Casoline Stations (1963).

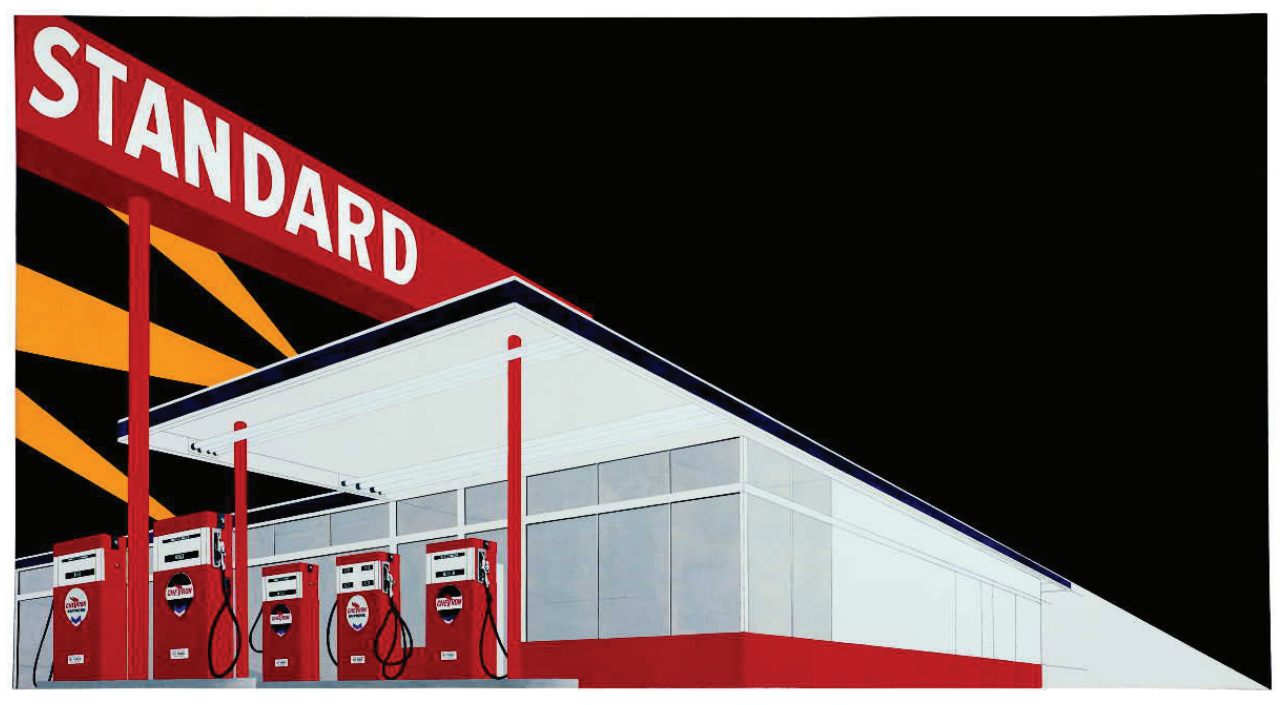

[Figura 05]

Ed Ruscha. Standard Station, Amarillo, Texas (1963).

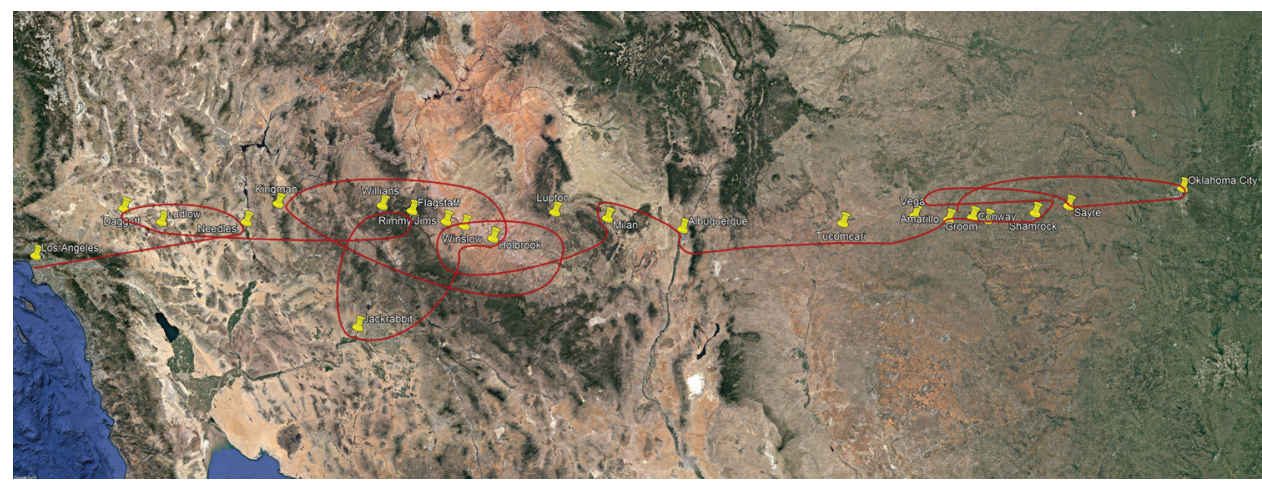

\section{[Figura 06]}

Imagem autoral tratada a partir de captura do Coogle Earth Pro usando as cidades presentes na rota de Twentysix Gas Stations como referência. 
informativo. Neste sentido, segundo CHEVIER e LINCWOOD (2004), Ruscha desloca a distinção tradicional entre ficção e documento ao se apropriar de referências linguísticas do fotojornalismo e de outros usos documentais ou funcionais da imagem, a exemplo de catálogos de imóveis ou fotos científicas, como estratégias de inventariamento de um mesmo tema com enquadramentos semelhantes em Thirtyfour Parking Lots in Los Angeles (1967) ${ }^{10}$. Utilizando um modo mínimo e objetivo de fotografar, aproxima-se do registro amador ao mesmo tempo que dele se distingue por utilizá-lo como parte de um processo de desconstrução do fotográfico como meio definidor de uma linguagem por si mesmo.

Nestes livros haveria então uma convergência entre a experiência fotográfica do entorno determinada pela cultura vernacular e a disciplina da arte conceitual, ao pensar a fotografia como um meio para transmitir determinada ideia ou conceito, uma tendência na qual Bernd e Hilla Becher ${ }^{11}$ seriam pioneiros com seus inventariamento experimentais a partir de 1957 e que posteriormente seria explorada por diversos artistas como Ruscha. Essa prática de inventariamento, para Hal Foster, seria assim uma espécie de paródia do fotojornalismo com sua forma despojada e o tema absurdo. Além de atribuir aos postos de gasolina um tipo de mapeamento sociológico implícito, relacionado ao desenvolvimento e às complexidades de um novo paradigma na arte contemporânea que ele nomeia de "artista como etnógrafo", sincrônico as mudanças culturais iniciadas na década de 1960.

O método utilizado durante o registro foi nomeado por Ruscha de antifotográfico, por privar as fotografias de sua qualidade artística, buscando o quanto possível a falta de profundidade nas imagens, para se aproximarem ao máximo das capturas feitas por pessoas não treinadas segundo os pressupostos estéticos na fotografia de arte. Em seu conjunto, essa estratégia de produção do artista coloca Ruscha na ambígua categorização situada entre o movimento Pop Art e a Arte Conceitual (GALLARDO e VECA, 2007). Ambos autores explicam seus livros como um registro de temas ordinários da paisagem do Oeste americano, interpretando a antifotografia de Ruscha como uma forma mais direta e estéril possível de representar esses cenários comuns, descrição que mais condiz com atitude dos artistas pop.

O enquadramento centralizado, a luz a pleno dia, a arquitetura genérica nenhum desses elementos condiz com a particularidade desejada na fotografia até aquele momento, são imagens de um humor irônico, indiferente, deadpan ${ }^{12}$, como uma relação de amor e ódio aos processos de urba-

\footnotetext{
10 Um livro com fotografias aéreas de trinta e quatro grandes parques de estacionamento em Los Angeles.

11 Inventariamentos fotográficos de estruturas industriais como Large, steel storage tank (1960).

12 Forma de humor sem variação de linguagem corporal ou emoção, contrastando com o ridículo do assunto, também chamado humor seco.
} 
nização acelerados encontrados em Los Angeles (WALDIE, 2016). Tal aspecto pode ser observado em muitas pinturas do artista, como na sequência de suas gravuras do letreiro de Hollywood ${ }^{13}$ sob o pôr do sol, onde alguns estão destruídos ou cobertos por poluição atmosférica, ou então na série de visões aéreas de estacionamentos do livro Thirtyfour parking lots in Los Angeles (1967). Para Waldie, as propostas de Ruscha criam um "sentido de lugar" que se recusa à reprodução de uma paisagem glamorosa ordinariamente exibida pela indústria cinematográfica e pelos anúncios publicitários. Diante da dualidade entre a Los Angeles real e sua imagem replicada pela indústria cultural ele escolhe o caráter árido das fotos para a representação de alguns dos seus elementos mais banais da cultura contemporânea.

Autocrítica da linguagem fotográfica

Há vários exemplos dessa mimeses amadorística do corpus do foto conceitualismo, e pode-se dizer que provavelmente quase todos os foto conceitualistas se entregam a ela em alguma medida. Mas um dos casos mais puros e mais exemplares é o conjunto de livros publicados por Edward Ruscha entre 1963 e $1970 .^{14}$

Se as opções de Ruscha apresentam uma visão sobre Los Angeles reveladora de suas dimensões não percebidas, aspecto semelhante pode-se reconhecer no uso que faz do meio fotográfico. Assim como Chevier e Lingwood, JEFF WALL (2017) reconhece uma abordagem foto conceitualista nos livros de Ruscha observada na relação paródica com a fotorreportagem, mas, particularmente, na mímesis amadora que ele associa a uma "redução" da linguagem fotográfica através da qual a fotografia realizaria sua autocrítica. Para Jeff Wall o aspecto seco dos fotolivros de Ruscha é um dos melhores exemplos dessa mímesis, que consiste num pastiche quanto ao modo do leigo fotografar e no consequente esvaziamento das convenções estéticas da foto artística, reportando, assim, a defasagem entre qualidades artesanais do registro da imagem e a difusão massiva de seu acesso pela população. Para Wall, esse "reducionismo" proposto por Ruscha é resultado de um processo que ele explica a partir de mudanças na fotografia entre as décadas de 1960 e 1970, quando se desenvolve um questionamento de sua estrutura, assim como fizeram a pintura e escultura, algumas décadas antes, para se afirmarem como uma arte modernista. 
A autocrítica da pintura e da escultura modernista optara por renunciar a figuração e a mímesis, já a fotografia não possui essa alternativa já que figurar um objeto faz parte de sua natureza como meio. Uma alternativa foi explorar a própria condição da foto como figuração que constitui um outro objeto que é plano, retangular e constituído por elementos de fatura industrial. Dentro desta alternativa, Wall considera duas direções que surgiram nesse processo, ambas convergem na produção de Ed Ruscha e poderiam ser pensadas também em interface com o artista como etnógrafo de Foster: 1) repensar a reportagem fotográfica colocando em questão a noção de documento visual; 2) pensar na desqualificação e requalificação do artista no contexto da indústria cultural.

Em Ruscha, como irá demonstrar Jeff Wall, a crítica se dará a um modelo dominante conhecido como fotografia humanista que ocupava um espaço proeminente nas revistas de circulação em massa como a Life nos EUA. O olhar deste tipo de fotógrafo é aquele que vai a caça, à espera precisa dos acontecimentos a serem dispostos no quadro. Para Wall, Twentysix Gas Stations implode a categoria do livro de fotografia, se referindo a produções mais próximas da fotorreportagem como de Walker Evans ${ }^{15}$ e Robert Frank ${ }^{16}$. Na escolha de construir um livro apenas com imagens de postos de gasolina, sem qualquer narrativa clara, e de representar os postos de maneira absurdamente asséptica e achatada, assim como argumenta Waldie, a atitude deadpan de Ruscha acaba por negar qualquer representação romantizada da paisagem.

Além disso, em seus dezesseis livros fotográficos, publicados entre os anos 1960 e 1970, o modo de produção e distribuição partilhava da lógica de qualquer outro objeto cotidiano, subvertendo o mercado de venda de imagens fotográficas artísticas impressas e com edição limitada. Eles são reproduzidos em série, mas sem identificação, impressos com uma qualidade média e de forma econômica e distribuídos com a cobrança de um pequeno valor. Com este modo de difusão, Ruscha ironizava a prática que restringia a circulação das fotografias as grandes galerias e lhes atribuía um valor especulativo amparado pela identificação com um número serial e limitação das cópias.

Ele reconhecia essa característica ao se referir aos snapshots de Twentysix Gas Stations como uma coleção de ready-mades ${ }^{17}$. A visão contrária a forma mercadológica que a fotografia artística difundia influenciou Ruscha na proposição de seus livros fotográficos, nos quais a imagem abdica de

\footnotetext{
15 Figura 07.

16 Figura 08.

17 Referência a intenção radical de Marcel Duchamp de romper com o artesanal do fazer artístico com a apropriação de elementos já feitos, produtos confeccionados pela indústria.
} 


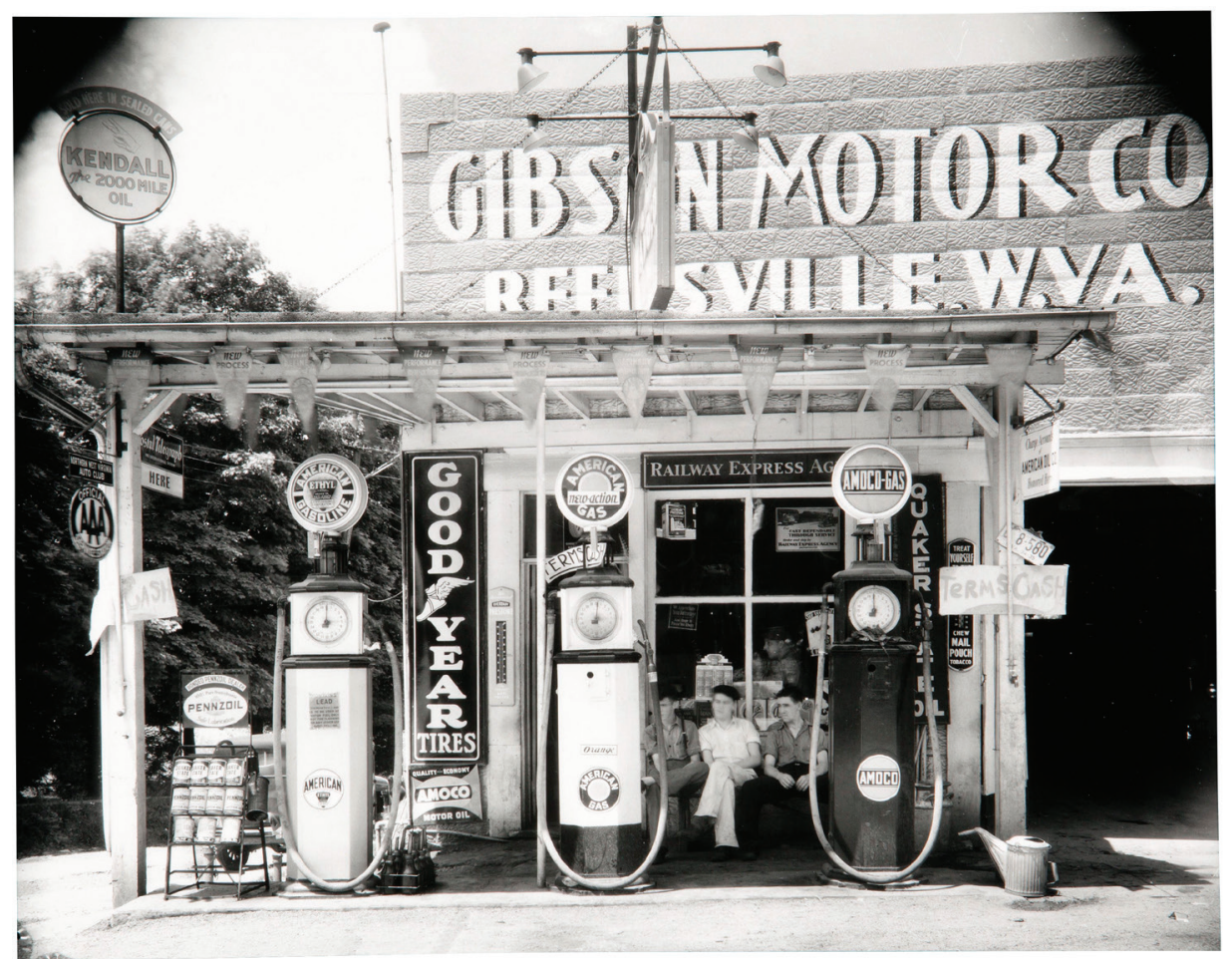

[Figura 07] Walker Evans (1903-1975). Gas Station, Reedsville, West Virginia, 1935.

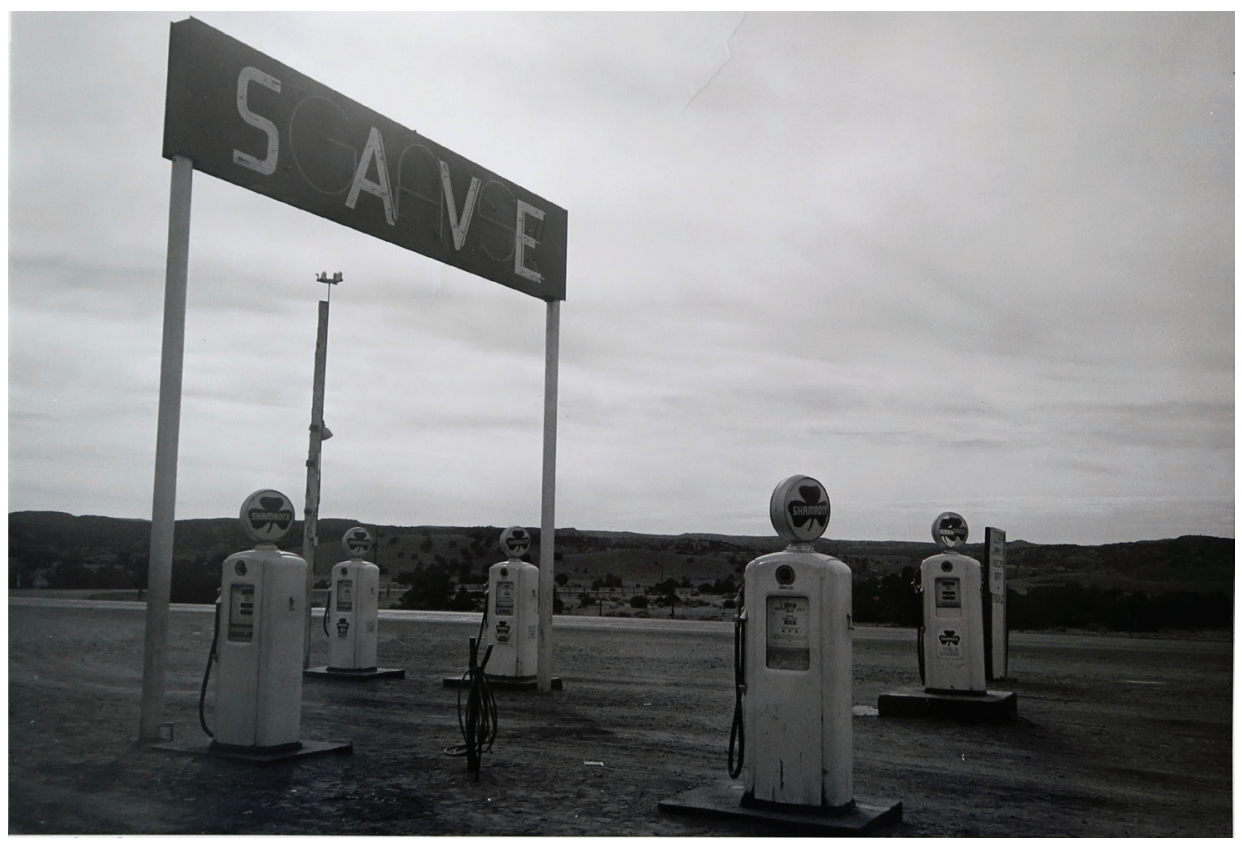

[Figura 08] Robert Frank. Santa Fe, New Mexico, 1955. 
sua "aura" artística para assumir um caráter objetal (tanto documental como uma referência direta a imagem da edificação, como de um objeto transladado para forma fotográfica) e mercadológico já que, em sua indissociabilidade, tanto a fotografia instantânea quanto o posto de gasolina estão imersos numa lógica de mercado.

\section{Considerações finais}

A aparente despretensiosa fotografia de Ruscha explorou a visualidade de espaços em ascensão, adaptados às exigências e à velocidade do uso massivo do automóvel. Também com especial atenção para os signos disseminados pelas mídias na construção de uma cultura visual e arquitetônica, Ruscha reflete sobre o sentido da forma fotográfica e do papel do artista no contexto da fotografia como um objeto de consumo e produção industrial em larga escala.

A reflexão dessas questões foi condicionada na forma do livro fotográfico, a partir do inventariamento monotemático, da fotografia lacônica, de reproduções econômicas das cópias e do uso específico do meio bibliográfico. Pois assim como Ruscha realiza um estranhamento no uso do aparato de fotografar pelo artista ele também o faz quanto a construção e a percepção de formato da mídia livro.

A compreensão de seu trabalho lança luz sobre a produção visual contemporânea que privilegia a dimensão objetual que a fotografia pode suscitar. Além disso, provoca uma revisão sobre uma concepção visual erigida sobre elementos de linguagem modernos, associados ao dispositivo, ao uso e à evidência de suas possibilidades estéticas e ao domínio da luz. Ao optar por uma "redução" do signo fotográfico, como sugere Jeff Wall, exige que façamos uma revisão nos conceitos que suportam esses signos e, pela negação, aponta para a necessidade da fotografia tornar evidente seus processos de significação e construção da imagem. 


\section{Bibliografia}

BENJAMIN, Walter. "A Obra de Arte na Era da sua Reprodutibilidade Técnica" (1936). Tradução de Gabriel Valladão Silva. L\&PM; Edição: Edição de bolso. Porto Alegre. 2018.

BREUER Karin; BROUGHER Kerry; WALDIE D.]; TERRY Collen. ED RUSCHA and the Great American West. Fine Arts Museum of San Francisco. University of Califórnia Press. 2016

CHEVRIER, J-F \& LINGWOOD, J. Outra Objetividade. In: Ribalta, J.(org.) Efecto real. Debates posmodernos sobre a fotografia. Barcelona: Gustavo Gili, 2004.

FOSTER, Hal. O retorno do Real: A vanguarda no final do século XX. Trad. Célia Euvaldo. São Paulo: Cosac Naify, 2014.

GALLARDO, Helena Perez. VEGA, Camelio. "Arte e fotografia (III). Cap. 11". In: SOUGEZ, Marie Loup (coord). História General de la Fotografia. Madri: Catedra Ediciones, 2007.

HARVEY, D. Condição Pós-Moderna. Uma pesquisa sobre as origens da mudança cultural. São Paulo: Edições Loyola, 1992.

SILVEIRA, Paulo. "As existências da narrativa no livro do artista." Tese apresentada para obtenção do título de doutor no Instituto de Artes da Universidade Federal do Rio Grande do Sul. 31 de Janeiro de 2008.

WALL, Jeff. Marcas da indiferença. aspectos da fotografia na, ou como, arte conceitual (1995). Revista de Fotografia Zum (12). São Paulo: Instituto Moreira Salles, 2017. 